\title{
Titanium doping effect on the characteristic properties of sol-gel deposited $\mathrm{ZnO}$ thin films
}

\author{
M. Yilmaz ${ }^{1,2 *}$, G. Turgut ${ }^{2,3}$ \\ ${ }^{1}$ Department of Elementary Science, K. K. Education Faculty, Ataturk University, Erzurum, 25240, Turkey \\ ${ }^{2}$ Advanced Materials Research Laboratory, Department of Nanoscience and Nanoengineering, \\ Graduate School of Natural and Applied Sciences, Ataturk University, 25240, Erzurum, Turkey \\ ${ }^{3}$ Department of Basic Sciences, Science Faculty, Erzurum Technical University, 25240 Erzurum, Turkey
}

Received 9 July 2014, received in revised form 16 February 2015, accepted 27 February 2015

\begin{abstract}
Undoped and $\mathrm{Ti}$ doped $\mathrm{ZnO}$ thin films were made by sol-gel spin coating, and the investigation of structural, morphological and optical features was applied as a function of the doping ratio. The films had a polycrystalline $\mathrm{ZnO}$ wurtzite crystal structure with (002) preferential direction and film crystallinity decreased with Ti doping content. The SEM studies indicated that the nanoparticle structure of undoped films changed to nano-network like structure with Ti doping. The transmittance and optical band gap of undoped sample firstly increased with 1 at.\% Ti doping and then they decreased with higher Ti level. Consequently, the present work suggests that the characteristic properties of $\mathrm{ZnO}$ can be tailored with Ti doping and $\mathrm{ZnO}: \mathrm{Ti}$ films have a potential importance for usage in many technological applications.
\end{abstract}

K e y w or d s: ZnO, sol-gel preparation, Ti doping, thin films

\section{Introduction}

Zinc oxide is one of the most studied metal-oxide semiconductors due to its low cost, easy fabrication, non-toxicity, good optical transparency in the visible region and low electrical resistivity [1-3]. These properties make it a good potential candidate for usage in the solar cells, diodes, photodetectors, sensors and liquid crystal displays [4-6]. $\mathrm{ZnO}$ is an n-type semiconductor due to the lack of stoichiometry, and the doping of $\mathrm{ZnO}$ can allow tailoring the characteristic properties of $\mathrm{ZnO}$. Titanium (Ti), which is one of the doping elements, has $4+$ oxidation states and if $\mathrm{Ti}^{4+}$ is replaced with $\mathrm{Zn}^{2+}$ ions in $\mathrm{ZnO}$ lattice, it gives extra free electrons, which causes an increase in electrical conductivity and optical transmittance.

The sol-gel spin coating is a widely used method to prepare $\mathrm{ZnO}$ thin film owing to its safety, easy manipulation, simplicity, low cost and easy control of deposition [7]. In the literature, there are a few previous studies on $\mathrm{Ti}$ doped $\mathrm{ZnO}$. However, there is no report on sol-gel deposition process of $\mathrm{Ti}$ doped $\mathrm{ZnO}$. Therefore, more studies should be conducted on $\mathrm{Ti}$ doping into $\mathrm{ZnO}$, and it is necessary to investigate the Ti doping effect on the features of $\mathrm{ZnO}$. In this study, we have deposited the $\mathrm{Ti}$ doped $\mathrm{ZnO}$ thin films by sol-gel spin coating, and we have examined the Ti doping effect on the structural, morphological and optical properties of $\mathrm{ZnO}$ thin films.

\section{Experimental}

In this research, undoped and $\mathrm{Ti}$ doped $\mathrm{ZnO}$ thin films were deposited on glass substrates by spin coating sol-gel method. $1 \mathrm{M}$ zinc acetate dehydrate $\left(\mathrm{Zn}\left(\mathrm{CH}_{3} \mathrm{COO}\right)_{2} \cdot 2 \mathrm{H}_{2} \mathrm{O}\right)$ and $1 \mathrm{M}$ titanium (IV) butoxide $\left(\mathrm{Ti}\left(\mathrm{OCH}_{2} \mathrm{CH}_{2} \mathrm{CH}_{2} \mathrm{CH}_{3}\right)_{4}\right)$ were dissolved in 2-Methoxyethanol $\left(\mathrm{C}_{3} \mathrm{H}_{8} \mathrm{O}_{2}\right)$ solvent, and monoethanolamine $\left(\mathrm{C}_{2} \mathrm{H}_{7} \mathrm{NO}\right.$, MEA) was separately added to this solution as stabilizer. The sol solutions at required quantities were mixed to prepare undoped, and $\mathrm{Ti}$ doped $\mathrm{ZnO}$ thin films. In the spin coating process, solutions were dropped on glass substrates, which were rotated at a speed of $3000 \mathrm{rpm}$ for $20 \mathrm{~s}$ by using a spin-coater and then the films were heated at

*Corresponding author: tel.: +90 44223142 69; fax: +90 44223609 55; e-mail addresses: mehmetyilmaz@atauni.edu.tr; yilmazmehmet32@gmail.com 
Table 1. Standard and calculated ' $d$ ' values of undoped and Ti doped ZnO thin films

\begin{tabular}{|c|c|c|c|c|c|c|c|}
\hline \multirow{2}{*}{ (hkl) } & \multirow{2}{*}{$\begin{array}{c}\text { Standard ' } d \text { ' } \\
(\mathrm{nm})\end{array}$} & \multirow{2}{*}{$\frac{\mathrm{ZO}}{d(\mathrm{~nm})}$} & \multirow{2}{*}{$\frac{\mathrm{TZO}-1}{d(\mathrm{~nm})}$} & \multirow{2}{*}{$\frac{\mathrm{TZO}-2}{d(\mathrm{~nm})}$} & \multirow{2}{*}{$\frac{\mathrm{TZO}-3}{d(\mathrm{~nm})}$} & \multirow{2}{*}{$\frac{\mathrm{TZO}-4}{d(\mathrm{~nm})}$} & \multirow{2}{*}{$\frac{\mathrm{TZO}-5}{d(\mathrm{~nm})}$} \\
\hline & & & & & & & \\
\hline (100) & 0.28143 & 0.27739 & 0.27698 & 0.27737 & 0.27752 & 0.27771 & 0.27789 \\
\hline$(002)$ & 0.26033 & 0.25670 & 0.25655 & 0.25689 & 0.25709 & 0.25721 & 0.25722 \\
\hline (101) & 0.24759 & 0.24413 & 0.24408 & 0.24461 & 0.24462 & 0.24497 & 0.24589 \\
\hline$(102)$ & 0.19111 & 0.18938 & - & - & - & - & - \\
\hline (110) & 0.16247 & 0.16101 & 0.16142 & 0.16142 & - & - & - \\
\hline (103) & 0.14771 & 0.14667 & 0.14650 & 0.14683 & - & - & - \\
\hline
\end{tabular}

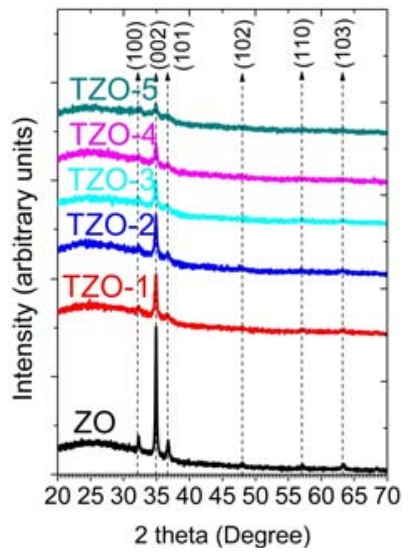

Fig. 1. XRD images of undoped and $\mathrm{Ti}$ doped $\mathrm{ZnO}$ thin films.

$200{ }^{\circ} \mathrm{C}$ for $5 \mathrm{~min}$. This procedure was repeated for 5 times and finally, they were annealed in air at $500^{\circ} \mathrm{C}$ for $30 \mathrm{~min}$. The undoped and 1, 2, 3, 4, 5 at.\% $\mathrm{Ti}$ doped films were named to be ZO, TZO-1, TZO-2, TZO-3, TZO-4, TZO-5, respectively. The characterization of films was made by X-ray diffraction (XRDRigaku Miniflex II diffractometer), scanning electron microscope (SEM-FEI inspect S50 SEM) and UV-VIS spectrophotometer (Perkin-Elmer, Lambda 40).

\section{Results and discussion}

\subsection{Structural properties}

The structural properties of undoped and Ti doped $\mathrm{ZnO}$ films were investigated by XRD. The XRD patterns of the samples (Fig. 1) indicate that the films have polycrystalline $\mathrm{ZnO}$ hexagonal wurtzite structure (JCPDS card file no. 36-1451) with (002) preferential orientation along $c$-axis. The preferred orientation of (002) was also observed by Liu et al. [8]. The peaks of (100), (101), (102), (110) and (103) are also observed for undoped $\mathrm{ZnO}$. The peaks of (102), (110) and (103) disappear when Ti atoms are inserted into the $\mathrm{ZnO}$ structure. The intensities of (100), (002) and
(101) peaks continuously decrease with Ti doping content, which suggests a decrease in the crystallinity of $\mathrm{ZnO}$ thin films. The interplanar distance ' $d$ ' values of films are determined by Bragg's law [9]:

$$
n \lambda=2 d \sin \theta
$$

where $n$ is one, $\lambda$ is the wavelength of the incident $\mathrm{X}$-ray beam that is $1.5418 \AA$, and $\theta$ is the diffraction angle. The calculated ' $d$ ' values are presented in Table 1, and these values are compared with the standard value which is taken from the JCPDS card no: 36-1451. The matching standard and calculated ' $d$ ' values also indicate that films have $\mathrm{ZnO}$ wurtzite structure. The lattice constants ' $a$ ' and ' $c$ ' of the $\mathrm{ZnO}$ wurtzite structure are identified by the relation [10]:

$$
\frac{1}{d^{2}}=\frac{4}{3}\left(\frac{h^{2}+k^{2}+h k}{a^{2}}\right)+\left(\frac{l^{2}}{c^{2}}\right)
$$

The lattice constant values of undoped and $\mathrm{Ti}$ doped $\mathrm{ZnO}$ thin films are tabulated in Table 2. The lattice constant values are found slightly lower than the standard values of $a_{0}=0.32498 \mathrm{~nm}$ and $c_{0}=$ $0.52066 \mathrm{~nm}$ (JCPDS card no: 36-1451). The lattice constants initially drop off with Ti doping and further Ti doping causes a continuous increment in lattice constant values. This can be resulted from the ionic radii of different oxidation states of titanium. At low doping levels, $\mathrm{Ti}^{4+}$ ions are probably replaced by $\mathrm{Zn}^{2+}$ ions and this causes a decrease in the lattice constant due to the lower ionic radius of $\mathrm{Ti}^{4+}(60.5 \mathrm{pm})$ than one of $\mathrm{Zn}^{2+}(74 \mathrm{pm})$ [11]. At high doping levels, $\mathrm{Ti}^{4+}$ ions can be reduced to $\mathrm{Ti}^{3+}(67 \mathrm{pm})$ or $\mathrm{Ti}^{2+}(86 \mathrm{pm})$ ions and this can give rise to an increase in the lattice constants owing to the fact that their ionic radii are higher than that of $\mathrm{Ti}^{4+}[11]$.

The strain of the $c$-axis $\left(\varepsilon_{z z}\right)$ can be determined by the formula [12]:

$$
\varepsilon_{z z}=\frac{c-c_{0}}{c_{0}} \times 100 \% .
$$

The strain values of all films are negative, which indicates compressive strains [13]. The compressive 
Table 2. Structural properties of undoped and $\mathrm{Ti}$ doped $\mathrm{ZnO}$ thin films

\begin{tabular}{|c|c|c|c|c|c|}
\hline \multirow{2}{*}{ Sample } & \multirow{2}{*}{ Strain $\varepsilon_{z z}(\%)$} & \multirow{2}{*}{ Grain size $D(\mathrm{~nm})$} & \multirow{2}{*}{ Dislocation density $\delta\left(\right.$ lines $\left.\mathrm{m}^{-2}\right)$} & \multicolumn{2}{|c|}{ Lattice constants } \\
\hline & & & & $a(\mathrm{~nm})$ & $c(\mathrm{~nm})$ \\
\hline $\mathrm{ZO}$ & -1.394 & 34.46 & $8.42 \times 10^{14}$ & 0.32044 & 0.51340 \\
\hline TZO-1 & -1.452 & 26.06 & $1.47 \times 10^{15}$ & 0.32041 & 0.51310 \\
\hline TZO-2 & -1.321 & 24.75 & $1.63 \times 10^{15}$ & 0.32119 & 0.51378 \\
\hline TZO-3 & -1.245 & 23.16 & $1.86 \times 10^{15}$ & 0.32113 & 0.51418 \\
\hline TZO-4 & -1.198 & 22.53 & $1.97 \times 10^{15}$ & 0.32168 & 0.51442 \\
\hline TZO-5 & -1.195 & 18.45 & $2.94 \times 10^{15}$ & 0.32324 & 0.51444 \\
\hline
\end{tabular}

strain value of -1.394 for undoped $\mathrm{ZnO}$ firstly rises to the value of -1.452 for TZO- 1 sample and then it continuously decreases to the values of $-1.321,-1.244$, -1.198 , and -1.194 for TZO-2, TZO-3, TZO-4, and TZO-5 samples.

The grain size and dislocation density values of films are calculated by Eqs. (4) and (5) [14]:

$$
\begin{gathered}
D=\frac{0.9 \lambda}{(\beta \cos \theta)}, \\
\delta=\frac{1}{D^{2}},
\end{gathered}
$$

where $D$ is grain size, $\delta$ is dislocation density, $\lambda$ is an $\mathrm{X}$-ray wavelength of $0.15418 \mathrm{~nm}, \beta$ is full width at half of the peak maximum (FWHM), and $\theta$ is Bragg's angle. The calculated grain size and dislocation density values are given in Table 2, and their variation with Ti doping is shown in Fig. 2. The grain size and dislocation density values are found to be $34.46 \mathrm{~nm}$ : $8.42 \times 10^{14}$ lines $\mathrm{m}^{-2}, 26.06 \mathrm{~nm}: 1.47 \times 10^{15}$ lines $\mathrm{m}^{-2}, 24.75 \mathrm{~nm}: 1.63 \times 10^{15}$ lines $\mathrm{m}^{-2}, 23.16 \mathrm{~nm}$ : $1.86 \times 10^{15}$ lines $\mathrm{m}^{-2}, 22.53 \mathrm{~nm}: 1.97 \times 10^{15}$ lines $^{-2}$ and $18.45 \mathrm{~nm}: 2.94 \times 10^{15}$ lines $\mathrm{m}^{-2}$ for ZO, TZO-1, TZO-2, TZO-3, TZO-4 and TZO-5 samples, respectively. The dislocation density can give information about crystallinity of a crystal, and it can be said that there is a decreasing crystallinity in the films with increasing $\mathrm{Ti}$ doping. The decreasing crystallinity may be resulted from probably improper lattice position of $\mathrm{Ti}$ atoms in $\mathrm{ZnO}$ structure. Decreasing crystallinity with Ti doping was also observed in the literature [15].

\subsection{Morphological properties}

Titanium doping effect on the morphological properties of $\mathrm{ZnO}$ thin films is determined by SEM micrographs. The SEM images (Fig. 3) show that all films are composed of nanoparticles and the surface morphology changes with Ti doping. The well-defined grains of the undoped sample are different from a forming nano-network structure with Ti doping. This nano-network structure is formed by collecting the

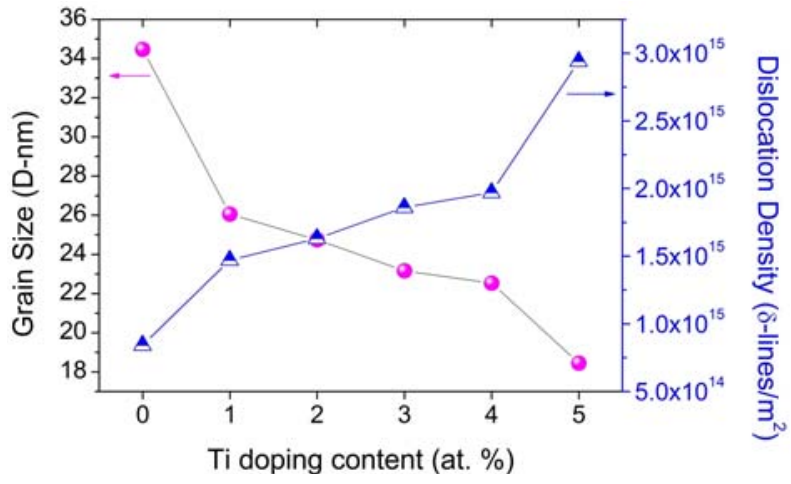

Fig. 2. The variation of grain size and dislocation density values of $\mathrm{ZnO}$ with $\mathrm{Ti}$ doping.

smaller grains together as soon as $\mathrm{Ti}$ is inserted to $\mathrm{ZnO}$. The network line thickness increases with the increasing Ti content. Similar nano-network structure was also observed by Keskenler et al. [16]. Observations from SEM micrographs suggest that Ti dopants in the growth process are very active [17] owing to changing film morphology.

\subsection{Optical properties}

Optical characterization of undoped and Ti doped films is made with UV/VIS spectrophotometer. Transmittance spectra of the films (Fig. 4) show that the transmittance of films ranges from 65 to $95 \%$ over the visible wavelength region. The transmittance of undoped sample firstly increases with 1 at.\% Ti doping and then it continuously decreases with the increasing Ti content. For ultraviolet region, the transmittance of undoped $\mathrm{ZnO}$ changes to shorter wavelengths with 1 at. $\% \mathrm{Ti}$ content (blue shift), then it changes to longer wavelengths with higher Ti level. To identify the absorption band edge of the films, the first derivative of the optical transmittance can be calculated. The curves of $\mathrm{d} T / \mathrm{d} \lambda$ vs. $h \nu$ have been drawn and represented in Fig. 5. According to other studies [18, 19], maximum peak values of the curves are related to the optical band gap energy and they shift to longer 


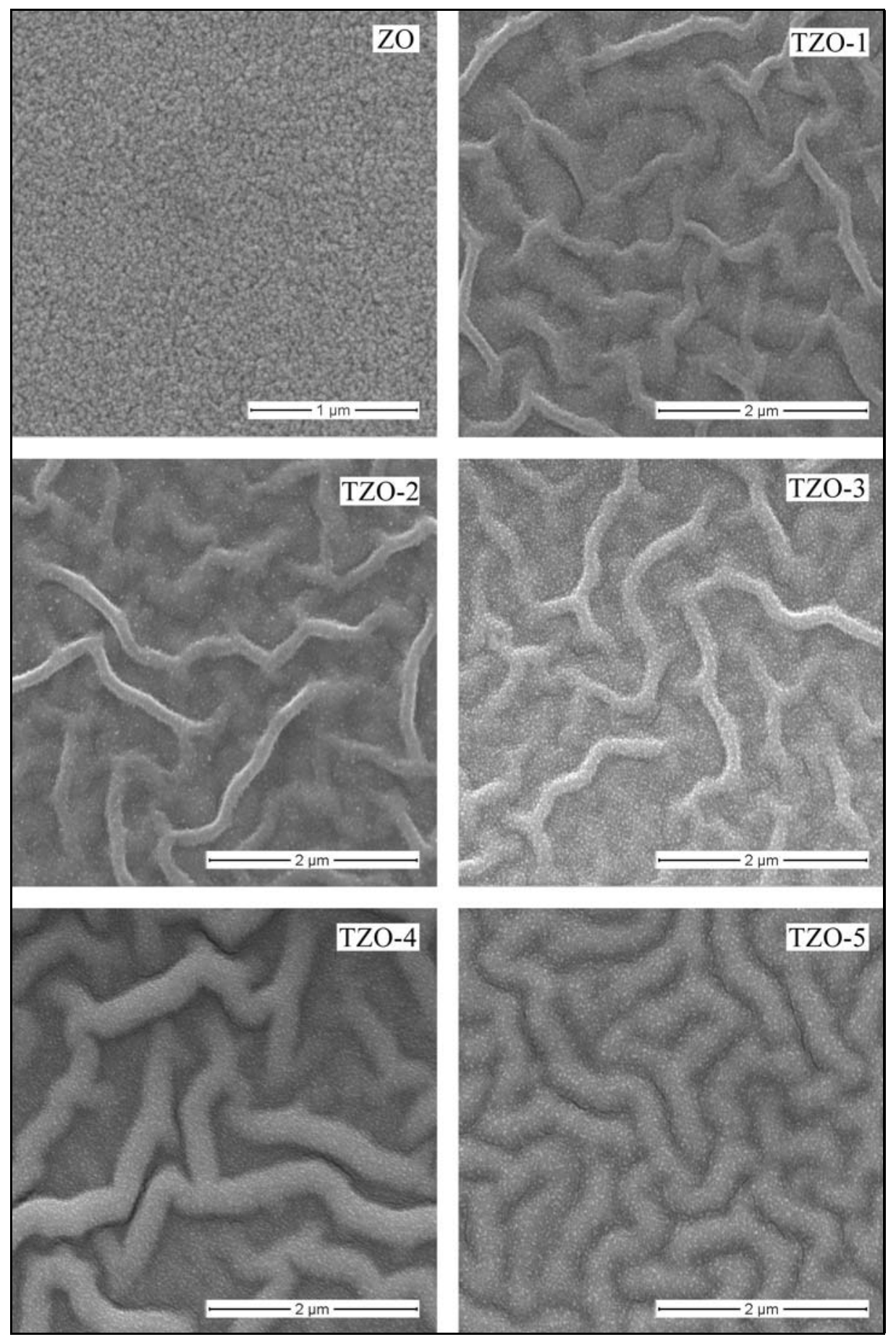

Fig. 3. SEM images of undoped and $\mathrm{Ti}$ doped $\mathrm{ZnO}$ thin films.

wavelengths with increasing Ti contents. This case can be clearly seen in Fig. 5. From Fig. 6, the maximum peak position is found to be $376,375,376,379,380$ and $382 \mathrm{~nm}$ for ZO, TZO-1, TZO-2, TZO-3, TZO-4 and TZO-5 samples, respectively. $E_{\mathrm{g}}$ values obtained from $\mathrm{d} T / \mathrm{d} \lambda$ curves are seen in Table 3 . Additionally, the optical band gap values have also been determined by inflexion point method [20, 21]. To calculate the optical band gap values in this method, following formula can be used:

$$
E_{\mathrm{g}}=\frac{1241.5}{\lambda_{\mathrm{c}}},
$$

where $\lambda_{c}$ is the critical wavelength described as the inflexion point of the UV absorption edge. In this method, the location of the $\lambda_{c}$ is important. For this purpose, the second derivative of the optical transmission should be calculated (Fig. 6). Optical band gap 

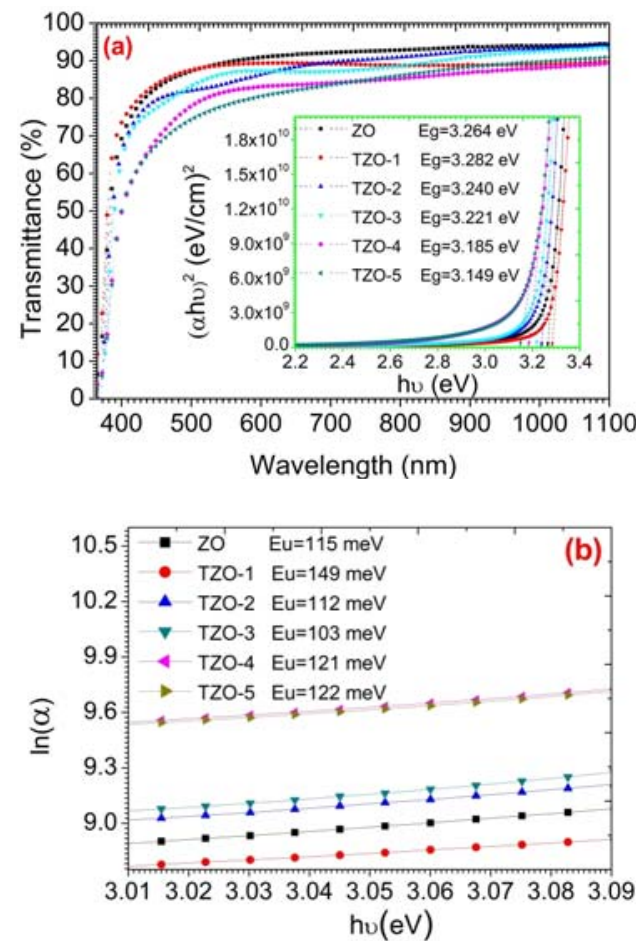

Fig. 4. (a) Optical transmittance (inset figure is $(\alpha h \nu)^{2}$ vs. $h \nu$ graph), (b) $\ln (a)$ vs. $h \nu$ graph of undoped and Ti doped $\mathrm{ZnO}$ thin films.

values that are obtained by an inflexion method are represented in Table 3. Besides, the optical band gap can be calculated more accurately. For this purpose $(\alpha h \nu)^{2}$ vs. $(h \nu)$ plot has been drawn. To make this, initially the absorption coefficient $(\alpha)$ is calculated by following relation [22]:

$$
\alpha=\ln (1 / T) / d
$$

then optical band gap values are obtained by equation

$$
\alpha h \nu=A(h \nu-E g)^{1 / 2} .
$$

In Eqs. (7) and (8), $T$ is a transmittance, $d$ is the film thickness, $h \nu$ is photon energy, $A$ is constant. The band gap $\left(E_{\mathrm{g}}\right)$ values are determined by drawing $(\alpha h \nu)^{2}$ vs. $(h \nu)$ (the inset graph in Fig. 4a). The identified band gap values of the films are given in Table 3, and their variation with Ti doping is shown in Fig. 7. The band gap value of undoped sample increases from 3.264 to $3.282 \mathrm{eV}$ with 1 at.\% Ti content, then it decreases with further Ti doping to the values of $3.240,3.221,3.185$ and $3.149 \mathrm{eV}$ for TZO-2, TZO-3, TZO-4 and TZO-5, respectively. The increasing band gap with Ti doping was also found in some studies $[8$, 23].

For semiconductors, fundamental absorption near the energy band gap increases exponentially, and the

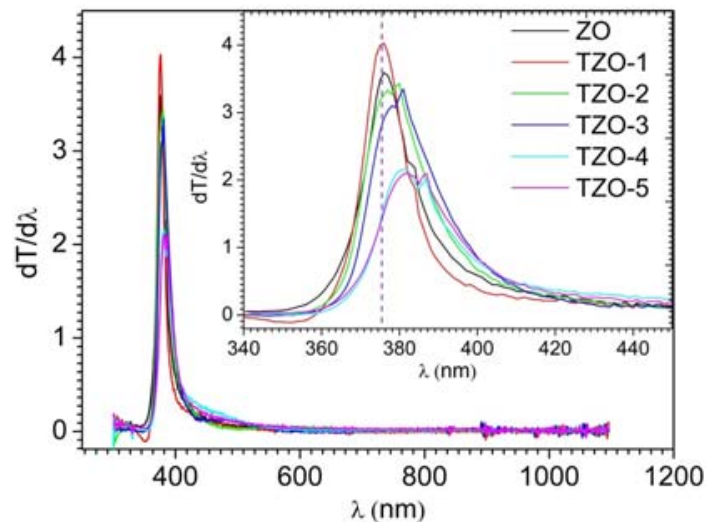

Fig. 5. Curves of $\mathrm{d} T / \mathrm{d} \lambda$ vs. wavelength of $\mathrm{Ti}$ doped $\mathrm{ZnO}$ thin films.

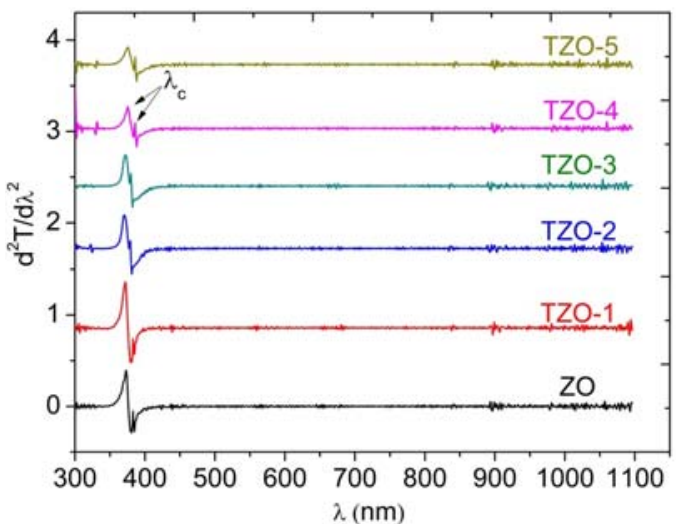

Fig. 6. The plot of $\mathrm{d}^{2} T / \mathrm{d} \lambda^{2}$ vs. wavelength of Ti doped $\mathrm{ZnO}$ thin films.

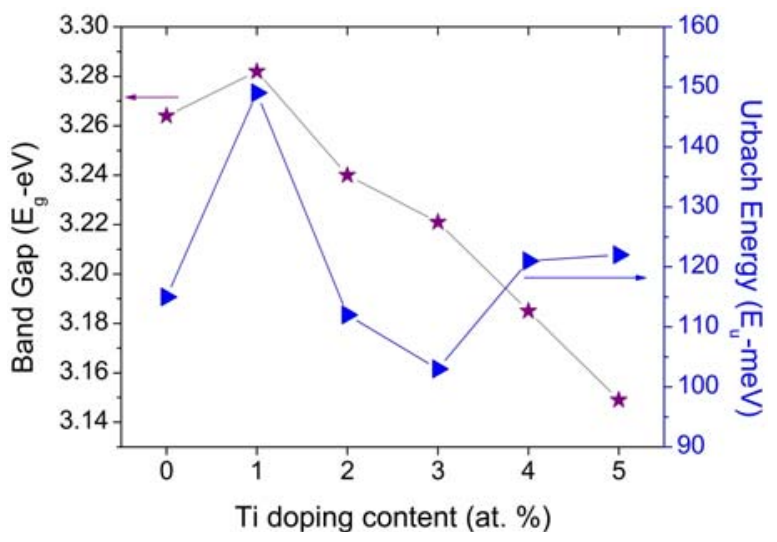

Fig. 7. The variation of optical band gap and Urbach energy values of undoped $\mathrm{ZnO}$ with $\mathrm{Ti}$ doping.

absorption edge is called the Urbach tail [24]. Urbach energy $\left(E_{\mathrm{u}}\right)$ indicates the width of the localized states in the band gap. It may be supposed as a parameter 
Ta ble 3. Optical parameters of undoped and $\mathrm{Ti}$ doped $\mathrm{ZnO}$ thin films

\begin{tabular}{|c|c|c|c|c|c|c|c|c|c|}
\hline \multirow{2}{*}{ Sample } & \multicolumn{3}{|c|}{ Transmittance values (\%) } & \multirow{2}{*}{$\lambda_{\mathrm{c}}(\mathrm{nm})$} & \multicolumn{3}{|c|}{ Function } & \multirow{2}{*}{$E_{\mathrm{u}}(\mathrm{meV})$} & \multirow{2}{*}{$\sigma\left(\times 10^{-1}\right)$} \\
\hline & at $450 \mathrm{~nm}$ & at $650 \mathrm{~nm}$ & at $850 \mathrm{~nm}$ & & $\begin{array}{c}(\alpha h \nu)^{2} \\
E_{\mathrm{g}}(\mathrm{eV})\end{array}$ & $\begin{array}{c}\mathrm{d} T / \mathrm{d} \lambda \\
E_{\mathrm{g}}(\mathrm{eV})\end{array}$ & $\begin{array}{c}\mathrm{d}^{2} T / \mathrm{d} \lambda^{2} \\
E_{\mathrm{g}}(\mathrm{eV})\end{array}$ & & \\
\hline $\mathrm{ZO}$ & 82.79 & 91.67 & 93.27 & 374 & 3.264 & 3.299 & 3.319 & 115 & 2.24 \\
\hline TZO-1 & 83.81 & 89.41 & 88.79 & 372 & 3.282 & 3.308 & 3.337 & 149 & 1.73 \\
\hline TZO-2 & 79.48 & 88.33 & 91.77 & 372 & 3.240 & 3.299 & 3.337 & 112 & 2.31 \\
\hline TZO-3 & 77.42 & 87.03 & 89.82 & 375 & 3.221 & 3.273 & 3.310 & 103 & 2.51 \\
\hline TZO-4 & 68.99 & 83.64 & 86.09 & 376 & 3.185 & 3.265 & 3.301 & 121 & 2.14 \\
\hline TZO-5 & 67.47 & 82.15 & 87.24 & 377 & 3.149 & 3.247 & 3.293 & 122 & 2.12 \\
\hline
\end{tabular}

containing the effects of all possible defects, and it depends on the degree of structural disorders. The Urbach energies are determined by following equation $[25]$ :

$$
\alpha=\alpha_{0} \exp \left(\frac{h v-E_{0}}{E_{\mathrm{u}}}\right),
$$

where $E_{0}$ and $\alpha_{0}$ are constants. The $E_{\mathrm{u}}$ is the Urbach energy that is designating the steepness of Urbach tail. If it takes the logarithm of Eq. (9), the following equation can be written:

$$
\ln \alpha=E \frac{1}{E_{\mathrm{u}}}\left(\ln \left(\alpha_{0}\right)+\frac{E_{0}}{E_{\mathrm{u}}}\right),
$$

where $E_{\mathrm{u}}$ is equal to the absorption edge energy width and inverse to the absorption edge slope value $E_{\mathrm{u}}^{-1}=$ $\Delta(\ln \alpha) / \Delta(h \nu) . E_{\mathrm{u}}$ energies of the films are calculated from the slope of the $\ln \alpha$ vs. photon energy $(h \nu)$ plot (Fig. 4b). The variations of calculated $E_{\mathrm{u}}$ values with Ti doping are given in Fig. 7. The $E_{\mathrm{u}}$ value of $115 \mathrm{meV}$ of the undoped film increases to the value of $149 \mathrm{meV}$ for TZO-1 sample and then it starts to decrease to the values of 112 and $103 \mathrm{meV}$ for TZO-2 and TZO-3 samples. When the $\mathrm{Ti}$ doping ratio is increased over 3 at.\% content, $E_{\mathrm{u}}$ values increase to 121 and $122 \mathrm{meV}$ in TZO-4 and TZO-5 samples.

The steepness parameter $(\sigma)$ of films is calculated by the following relation:

$$
\sigma=k_{\mathrm{B}} T / E_{\mathrm{u}}
$$

where $k_{\mathrm{B}}$ is Boltzmann constant, $T$ is temperature at $300 \mathrm{~K}$. The $\sigma$ value of undoped $\mathrm{ZnO}$ decreases from $2.24 \times 10^{-1}$ to $1.73 \times 10^{-1}$ for TZO-1, and then it increases to the values of $2.31 \times 10^{-1}, 2.51 \times 10^{-1}$ in TZO-2, TZO-3 samples. Finally, it starts to decrease to the values of $2.14 \times 10^{-1}$ and $2.12 \times 10^{-1}$ in TZO-4 and TZO-5 films. There are many determinants affecting the optical band gap of $\mathrm{ZnO}$ such as non-stoichiometry, grain size, disorders, lattice parameters and carrier concentration [26, 27].
According to $E_{\mathrm{u}}$ values, $E_{\mathrm{g}}$ value of undoped $\mathrm{ZnO}$ would decrease with 1 at. $\%$ Ti doping due to structural disorders and transitions from band to tail and tail to tail [28]. The increasing $E_{\mathrm{g}}$ values with 1 at.\% Ti doping are probably resulting from the Moss-Burstein (MB) effect [29]. In the $\mathrm{MB}$ effect, $\mathrm{Zn}^{2+}$ ions are replaced by $\mathrm{Ti}^{4+}$ ions, and this introduces an increase in the carrier density. Thus, Fermi level lifts into the conduction band, and optical band gap rises. The decreasing optical band gap with the increasing $\mathrm{Ti}$ content can be resulted from the increasing structural disorders, lattice imperfections and decreasing crystallinity, which can be seen from XRD results, and transitions from band to tail and tail to tail.

\section{Conclusions}

Fabrication and investigation studies on $\mathrm{Ti}$ doped $\mathrm{ZnO}$ thin films by sol-gel spin coating technique were made as a function of Ti doping ratio. The XRD studies showed that $\mathrm{Ti}$ doped $\mathrm{ZnO}$ thin films with polycrystalline structure had (002) preferential orientation, and the film crystallinity decreased with Ti doping. From SEM micrographs, it was seen that the nanoparticle structure of undoped $\mathrm{ZnO}$ changed to nano-network structure when $\mathrm{Ti}$ atoms were inserted into the $\mathrm{ZnO}$ structure. The optical transmittance and band gap values of undoped $\mathrm{ZnO}$ initially increased with 1 at.\% Ti content, but then further $\mathrm{Ti}$ doping caused a decrease in optical transmittance and band gap values. Urbach energy and steepness parameter values were also studied, and it was found that they depended on $\mathrm{Ti}$ doping content. The results obtained have proved that $\mathrm{Ti}$ doped $\mathrm{ZnO}$ films can be successfully grown by a sol-gel spin coating method, and these films can be useful for many optoelectronic device applications.

\section{Acknowledgement}

This research was supported by the Ataturk University Research Fund, Project Number 2013/152. 


\section{References}

[1] Pawar, B. N., Ham, D.-H., Mane, R. S., Ganesh, T., Cho, B. W., Han, S. H.: Appl. Sur. Sci., 254, 2008, p. 6294. doi:10.1016/j.apsusc.2008.02.088

[2] Chouikh, F., Beggah, Y., Aida, M. S.: J. Mater. Sci: Mater., 22, 2011, p. 499. doi:10.1007/s10854-010-0167-y

[3] Iribarren, A., Fernández, P., Piqueras, J.: Superlatt. Microstruc., 43, 2008, p. 600. doi:10.1016/j.spmi.2007.06.009

[4] Sanchez-Juarez, A., Tiburcio-Silver, A., Ortizc, A., Zironi, E. P., Rickards, J.: Thin Solid Films, 333, 1998, p. 196. doi:10.1016/S0040-6090(98)00851-7

[5] Keskenler, E. F., Dogan, S., Turgut, G., Gurbulak, B.: Metall. Mater. Trans. A, 43A, 2012, p. 5088. doi:10.1007/s11661-012-1365-4

[6] Ilican, S., Caglar, Y., Caglar, M., Yakuphanoglu, F.: Appl. Surf. Sci., 255, 2008, p. 2353. doi:10.1016/j.apsusc.2008.07.111

[7] Turgut, G., Keskenler, E. F., Aydın, S., Dogan, S., Duman, S., Sonmez, E., Esen, B., Duzgun, B.: Mater Lett., 102-103, 2013, p. 106. doi:10.1016/j.matlet.2013.03.125

[8] Liu, X., Hu, M., Chu, X., Yan, Q.: J Mater Sci: Mater Elec., 24, 2013, p. 2839. doi:10.1007/s10854-013-1180-8

[9] Tilley, R. J. D.: Crystals and Crystal Structures. West Sussex, John Wiley \& Sons Ltd. 2006.

[10] Turgut, G., Keskenler, E. F.: J. Mater. Sci.: Mater., 25, 2014, p. 273. doi:10.1007/s10854-013-1583-6

[11] Greenwood, N. N., Earnshaw, A.: Chemistry of the Elements. 2nd Edition. Oxford, Reed Educational and Professional Publishing 1997.

[12] Raoufi, D., Raoufi, T.: Appl. Surf. Sci., 255, 2009, p. 5812. doi:10.1016/j.apsusc.2009.01.010

[13] Ismail, A., Abdullah, M. J.: J. King Saud Univ. Sci., 25, 2013, p. 209. doi:10.1016/i.jksus.2012.12.004

[14] Yilmaz, M.: Phys. Scr., 89, 2014, p. 095802. doi:10.1088/0031-8949/89/9/095802
[15] Liu, J., Ma, S. Y., Huang, X. L., Ma, L. G., Li, F. M., Yang, F. C., Zhao, Q., Zhang, X. L.: Superlatt. Microstruc., 52, 2012, p. 765. doi:10.1016/j.spmi.2012.06.021

[16] Keskenler, E. F., Turgut, G., Doğan, S.: Superlatt. Microstruc., 52, 2012, p. 107. doi:10.1016/j.spmi.2012.04.002

[17] Chakraborty, A., Mondal, T., Bera, S. K., Sen, S. K., Ghosh, R., Paul, G. K.: Mater. Chem. Phys., 112, 2008, p. 162. doi:10.1016/j.matchemphys.2008.05.047

[18] Tsay, C. Y., Hsu, W. T.: Ceram. Inter., 39, 2013, p. 7425. doi:10.1016/j.ceramint.2013.02.086

[19] Ilican, S., Caglar, Y., Caglar, M.: J. Optoelec. Advan. Mater., 10, 2008, p. 2578.

[20] Dolbec, R., Khakani, M. A. El, Serventi, A. M., Trudeau, M., Saint-Jacques, R. G.: Thin Solid Films, 419, 2002, p. 230. doi:10.1016/S0040-6090(02)00769-1

[21] Dhakal, T. P., Peng, C. Y., Tobias, R. R., Dasharathy, R., Westgate, C. R.: Solar Energy, 100, 2014, p. 23. doi:10.1016/j.solener.2013.11.035

[22] Tauc, J., Grigorovici, R., Vancu, A.: Phys. Status Solidi B, 15, 1966, p. 627. doi:10.1002/pssb.19660150224

[23] Zhong, Z. Y., Zhang, T.: Mater Lett., 96, 2013, p. 237. doi:10.1016/j.matlet.2013.01.025

[24] Urbach, F.: Phys. Rev., 92, 1953, p. 1324. doi:10.1103/PhysRev.92.1324

[25] Meulenkamp, E. A.: J. Phys. Chem. B, 103, 1999, p. 7831. doi:10.1021/jp9914673

[26] Xu, H. Y., Liu, Y. C., Mu, R., Shao, C. L., Lu, Y. M., Shen, D. Z., Fan, X. W.: App. Phys. Lett., 86, 2005, p. 123107. doi:10.1063/1.1884256

[27] Lee, Y. H., Lee, W. J., Kwon, Y. S., Yeom, G. Y., Yoon, J. K.: Thin Solid Films, 341, 1999, p. 172. doi:10.1016/S0040-6090(98)01518-1

[28] Santhosh, V. S., Babu, K. R., Deepa, M.: J. Mater. Sci.: Mater. Elec., 25, 2014, p. 224. doi:10.1007/s10854-013-1576-5

[29] Burstein, E.: Phys. Rev., 93, 1954, p. 632. doi:10.1103/PhysRev.93.632 